\title{
SUGESTÃO DE IMPLANTAÇÃO DA METODOLOGIA BIM NO CURSO DE ENGENHARIA CIVIL DA UNIVERSIDADE FEDERAL DO CEARÁ
}

Luciano H. C. H. Sousa-lucianohamed@alu.ufc.br

Sabrina R. Gonçalves - sabrinarg57@gmail.com

CamilyV.Barbosa-vasconcelosmily@alu.ufc.br

Antonio P. H. Cavalcante-apaulo@det.ufc.br

Departamento de Integração Acadêmica e Tecnológica - DIATEC

UFC. Campus do Pici, Bloco 710, 1o Andar

CEP 60455760 - Fortaleza - Ceará

\section{Resumo:}

No contexto da Indústria 4.0, tem-se a necessidade de desenvolver cada vez mais depressa soluções para as dores que surgem a cada dia na esfera global. Diante disso, no setor da Engenharia Civil, sobretudo, na formação da Universidade Federal do Ceará, o profissional encontra dificuldades de atuar de forma satisfatória com a gama de tecnologias que vem surgindo e a letargia da universidade em acompanhar esse avanço no processo de construção do profissional. Este trabalho objetiva propor uma sugestão de implantação da metodologia BIM de forma integrada na grade curricular do curso de Engenharia Civil da Universidade Federal do Ceará. A metodologia consistiu na revisão bibliográfica do Projeto Político Pedagógico-PPP, bem como das Diretrizes Curriculares Nacionais-DCNs, além da revisão bibliográfica de competências e habilidades que se relacionam com a metodologia BIM, aliando a isso metodologias ativas de ensino-aprendizagem consagradas na pedagogia. Espera-se que a contribuição ajude no processo de reforma curricular do curso de Engenharia Civil em que o profissional tenha uma formação mais atualizada e próxima da realidade em que vivemos.

Palavras-chave: BIM, Engenharia Civil, UFC, Metodologia ativa, ensino.

\section{INTRODUÇÃO}

Segundo o site institucional da Universidade Federal do Ceará, o Engenheiro Civil é um profissional chave no desenvolvimento uma vez que sua atribuição é estudar formas eficientes de construir. Com isso, ele atua no projeto de pontes, viadutos, barragens, edifícios, rodovias, estradas, dentre outras obras. Suas atividades começam antes da realização dos trabalhos, com o estudo dos solos das futuras instalações, análise de materiais e equipamentos a serem utilizados e definição de cronograma e seguem durante a construção, com a supervisão e definição dos esquemas de edificação e até mesmo após, com os serviços de manutenção da infraestrutura, gerenciamento de ocupação e reformas. Cabe ao engenheiro especificar as redes de instalação elétrica, hidráulica e de saneamento, calcular os gastos, avaliar os efeitos das intempéries sobre os materiais e realizar ações que garantam a segurança nos canteiros de obra. Outros campos para o graduado incluem o desenvolvimento de materiais, além de assistência 
técnica, consultoria e avaliações. Com efeito, é notória a importância deste profissional para a sociedade, e para tanto, é necessário que sua formação seja construída acompanhando os diversos avanços tecnológicos que estamos vivendo.

Para Linsingen, I. V. et al (1999), o ensino de engenharia é centrado na adoção de uma postura filosófica positivista que permeia tanto a profissão como seu ensino, como consequência, tem-se um viés objetivo da avaliação e do aprendizado. Ainda segundo os autores, só admitindo as 'verdades científicas', e excluindo qualquer possibilidade de conhecimento por meio metafísico, esta visão filosófica contribuiria para um maior fechamento da profissão. No cenário atual do curso de engenharia civil da UFC, temos uma grade curricular que foi modelada em outubro de 2004, segundo o Projeto Político Pedagógico do curso. Essa grade, além de não contemplar os avanços tecnológicos que tivemos nos últimos 15 anos, apresenta a problemática de que os conteúdos não são interligados entre si, salvo poucas exceções. Na visão de Koehler et al. (2012), com o ensino contextualizado e integrado, os alunos são instigados a estudar conteúdos e buscar a solução de questões reais pertinentes a um possível campo de trabalho. Esta visão vai de encontro à postura de ensino positivista adotada desde o século XIX, influenciada pelo filósofo Auguste Comte (1798- 1857).

Nesse sentido, temos a estratégia BIM BR que surgiu em 2018, por iniciativa do governo federal, que em 2019 foi atualizada sob o decreto $\mathrm{N}^{\circ}$ 9.983, de 22 de agosto de 2019 e que tem como finalidade promover um ambiente adequado ao investimento em BIM e sua difusão no país. Em seu quarto objetivo, cita o estímulo à maior inserção do BIM nas disciplinas de graduação e pós-graduação em Engenharia e Arquitetura. A Modelagem da Informação da Construção (BIM) é definida por Bilau Succar como um conjunto de procedimentos técnicos e processuais, uma inovação na indústria da construção. É uma metodologia para gerar, trocar e gerenciar os dados de um empreendimento construído ao longo de seu ciclo de vida. (SUCCAR, 2014).

Tangente a isso, outra iniciativa do governo surge no tocante ao desenvolvimento da indústria 4.0 no país. Segundo o portal institucional da Indústria 4.0, o Ministério do Desenvolvimento, Indústria e Comércio Exterior (MDIC) instituiu, em junho de 2017, o Grupo de Trabalho para a Indústria 4.0 (GTI 4.0), com o objetivo de elaborar uma proposta de agenda nacional para o tema. O GTI 4.0 possui mais de 50 instituições representativas (governo, empresas, sociedade civil organizada, etc), por onde ocorreram diversas contribuições e debates sobre diferentes perspectivas e ações para a Indústria 4.0 no Brasil. No cerne desta análise, se mostra a importância do que está acontecendo na esfera tecnológica brasileira. Segundo PEREIRA(2018 Apud RÜßMANN et al., 2015) dentre os pilares da indústria 4.0 temos:

1. Big data e análise de dados: grandes quantidades de dados sobre a manufatura podem ser obtidos de diversas fontes, como os equipamentos de produção, sistemas de gestão de empresas e clientes, analisados e, assim, utilizados para a tomada de decisão em tempo real.

2. Robôs autônomos: robôs já são utilizados na indústria, porém eles tendem a ser mais autônomos, podendo trabalhar ao lado dos humanos de forma segura, custando menos e tendo maiores capacidades.

3. Simulação: a tomada de decisão poderá ser auxiliada pelas simulações, que utilizarão informações obtidas em tempo real. A otimização de parâmetros poderá ser feita a partir de testes de otimização, feitos com modelos virtuais.

4. Integração de sistemas horizontal e verticalmente: sistemas estarão mais integrados, até mesmo em redes intercompanhias, o que possibilitará maior automação.

5. A Internet das Coisas Industrial: a interação entre os mais diversos equipamentos será obtida pela Internet das Coisas Industrial, conectando equipamentos com processamento embarcado, auxiliando a obtenção de respostas em tempo real. 
6. Segurança cibernética: a maior conectividade demandará maiores proteções contra ataques cibernéticos, e, assim, impulsiona a construção de novas tecnologias para este fim.

7. Nuvem: O uso da computação em nuvem, que já vem sendo utilizada em aplicações empresariais e análise de dados, aumentará com a Indústria 4.0, contribuindo para ganhos em performance das tecnologias envolvidas, auxiliando questões entre companhias.

8. Fabricação de aditivos: a Indústria 4.0 possibilitará a construção de produtos customizados, de forma descentralizada, reduzindo despesas com estoque, a partir do uso de tecnologias como as impressoras 3D.

9. Realidade aumentada: a tomada de decisão e o desenvolvimento de procedimentos serão auxiliados pela realidade aumentada, que suporta uma grande variedade de sistemas.

Conforme Caruso (2017), mudanças proporcionadas pelo desenvolvimento da indústria 4.0 exigirão dos profissionais habilidades de resolução de problemas, criatividade, habilidades cognitivas, linguísticas e sociais.

Bialoń e Werner (2018), reforçam a necessidade de desenvolver habilidades de resolução de problemas, pensamento crítico e análise de informações, além de habilidades sociais de cooperação. Ainda segundo Bialoń e Werner (2018), para que haja o desenvolvimento dessas competências é necessário que haja uma mudança não apenas no método de ensino, mas também no programa educacional. Cabe, portanto, às escolas e às universidades desenvolverem planos a fim de formar pessoas com competências que atendam ao mercado.

Quanto ao desenvolvimento de BIM, Succar (2014) lista algumas competências necessárias, sendo estas da área gerencial, administrativa e funcional. Na área gerencial, Succar aborda a liderança, planejamento estratégico e a gestão organizacional. Já na área administrativa, fala sobre políticas e procedimentos, finanças e contabilidade e gestão de recursos humanos. Na área funcional cita a colaboração, gerenciamento de equipe e de fluxo de trabalho e senso de liderança em projetos colaborativos. Segundo a filosofia freiriana (FREIRE, 2010, p.47) ensinar não é transferir conhecimento, mas criar as possibilidades para a sua própria produção ou a sua construção. Dessa forma, a fim de desenvolver as competências citadas ainda durante a faculdade, é necessário que haja uma reestruturação da metodologia de ensino adotada, de forma que o aluno, no decorrer da graduação construa seu próprio conhecimento sob a orientação dos professores.

Diante disso, este trabalho objetiva elaborar uma proposta de implementação da metodologia BIM no decorrer da grade curricular do curso de Engenharia Civil do Centro de Tecnologia da Universidade Federal do Ceará de forma que haja uma maior participação dos alunos na construção do ensino.

\section{METODOLOGIA}

A metodologia consistiu no levantamento das informações relacionadas ao PPP-Projeto Político Pedagógico do curso de Engenharia Civil da Universidade Federal do Ceará, tais como as ementas das disciplinas, os pré-requisitos e as justificativas, bem como, das DCNs-Diretrizes Curriculares Nacionais. Além disso, no presente trabalho baseou-se em metodologias de ensino aprendizagem, ressaltando a teoria das competências de Philippe Perrenoud e a pedagogia libertadora de Paulo Freire. Ademais, baseada na teoria das competências das áreas gerencial, administrativa e funcional de Bilau Succar, alinhada aos pilares da Indústria 4.0, será proposta uma sugestão de implantação da metodologia BIM no decorrer da grade curricular, de forma integrada. 
Para a implantação, sugere-se que seja executada de forma gradativa para que seja totalmente cumprida em um prazo de 5 anos. Pode ser subdividida em três grupos de itens: processos, pessoas e tecnologia.

No tocante aos processos, serão estabelecidos fluxos de trabalhos colaborativos interdisciplinares, de forma que os alunos possam desenvolver o trabalho em equipe e a comunicação. Além disso, sugere-se que o discente seja encorajado a desenvolver um mapeamento de processos relacionados ao trabalho final de cada disciplina, tais como a interoperabilidade, conceitos e ferramentas de gerenciamento BIM, implementação de BIM, estudos de casos, processo de formação de equipes e dinâmicas de equipes (Barison, M. B., \& Santos, E. T, 2011). Além disso, é esperado que os estudantes, em grupos, estabeleçam previamente padrões a serem seguidos, de forma a mostrar a importância dessas práticas no mercado de trabalho.

No que tange a pessoas, serão desenvolvidos treinamentos para os docentes em fluxo de trabalho colaborativo, metodologia BIM e ainda, uso de ferramentas BIM com foco em cada disciplina. Cruz, Cuperschmid e Ruschel (2017) comentam sobre a experiência de atualização de docentes com treinamentos oferecidos por professores da própria instituição, seminários com profissionais externos, cursos sobre diversas tecnologias que dão suporte ao BIM e sobre como essas ações proporcionaram a oportunidade de disseminação de conhecimento específico sobre BIM para os docentes. Nesta proposta, é encorajada uma parceria com as empresas de software para o fornecimento de suporte aos estudantes e professores.

Em relação a tecnologia, deve ser realizado um diagnóstico dos laboratórios disponíveis para o curso e verificar quais atendem os requisitos mínimos para cada software que será utilizado a depender do foco de cada disciplina. Deve-se ainda escolher prioritariamente os softwares, mais utilizados pelo mercado que não constitua ônus nas licenças estudantis tanto para os discentes e docentes, como para a instituição. Caberá ao coordenador do curso, desenvolver as articulações necessárias, bem como buscar apoio para parcerias públicoprivadas, para auxiliar no processo de implantação, e ainda, contar com o apoio de ações de extensão, indo ao encontro das DCNs, que em seu Art. $6^{\circ}$ mostra que é necessário estimular atividades contextualizadas entre a teoria e a aplicação prática para que sejam desenvolvidas as competências necessárias estabelecidas no perfil do egresso, incluindo ações de extensão e a integração empresa escola (BRASIL. Ministério da Educação, 2019). Para validação da implantação utilizada, o processo deverá ser acompanhado por um grupo composto por alunos, professores, coordenador do curso e profissionais do mercado que atuam diretamente no setor de implantação de BIM pelo período de 5 anos.

\section{DISCUSSÃO}

No curso de Engenharia Civil da UFC, as disciplinas da grade curricular não são, em sua maioria, interligadas de forma que os conteúdos são fragmentados e a construção do conhecimento fica um pouco mais trabalhosa entre os discentes do curso. Uma das formas de facilitar o entendimento dos discentes, é o uso do construtivismo de Paulo Freire, onde no processo de alfabetização de adultos utilizava elementos do cotidiano para que seus alunos compreendessem o que lhes era ensinado (FREIRE, 2010).

Para a sugestão de implantação utilizou-se a grade curricular atual, mas com uma proposta de integração entre as disciplinas no decorrer do curso, inserindo a abordagem da metodologia BIM por meio de metodologias ativas, de forma que organizou-se na ordem cronológica do curso as sugestões de integrações. 
Iniciando pelo primeiro ano (Figura 01), tem-se as disciplinas de Desenho para Engenharia, Introdução a Engenharia e Programação.

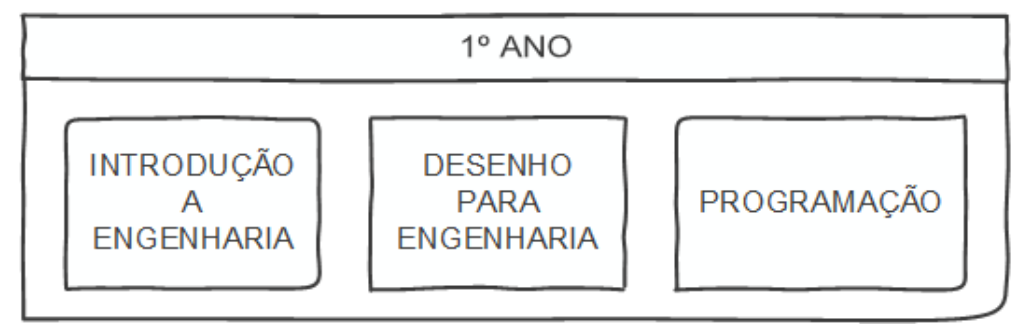

Figura 01: Disciplinas do $1^{\circ}$ ano do curso de engenharia que podem ser relacionadas a metodologia BIM.

$\mathrm{Na}$ disciplina de Introdução a Engenharia, além dos assuntos já abordados, seriam tratados os conceitos de BIM, de indústria 4.0 e os campos de aplicações nos diversos setores da Engenharia Civil, como construção civil e infraestrutura por exemplo. Paralelo a isso, na disciplina de Programação cuja linguagem ensinada atualmente é Python, seria abordada a criação de códigos focados na automatização de projetos em ferramentas BIM e introdução ao machine learning que está sendo cada vez mais utilizado no cenário da metodologia BIM e da indústria 4.0. Tangente a isso, na disciplina de Desenho para Engenharia, na qual, atualmente, tem-se como trabalho final o desenho a mão e o desenho auxiliado por computador, poderiam ser utilizados os programas desenvolvidos na disciplina de programação para a automatização do projeto e ao fim da disciplina a entrega ser um projeto tal qual como praticado no mercado de trabalho. Além das atividades práticas, durante o decorrer do semestre os trabalhos finais seriam desenvolvidos de maneira progressiva, de forma que o aluno vai construindo o conhecimento de forma ativa com a orientação de seus professores e desenvolvendo o pensamento crítico, ao passo que trabalha colaborativamente com os colegas para a evolução do senso de crescimento em equipe, que é extremamente relevante na formação do profissional de engenharia atualmente.

Já no segundo ano do curso (Figura 02), tem-se mais três disciplinas que podem ser relacionadas diretamente com a metodologia BIM: Eletrotécnica, Fundamentos de Administração e Topografia.

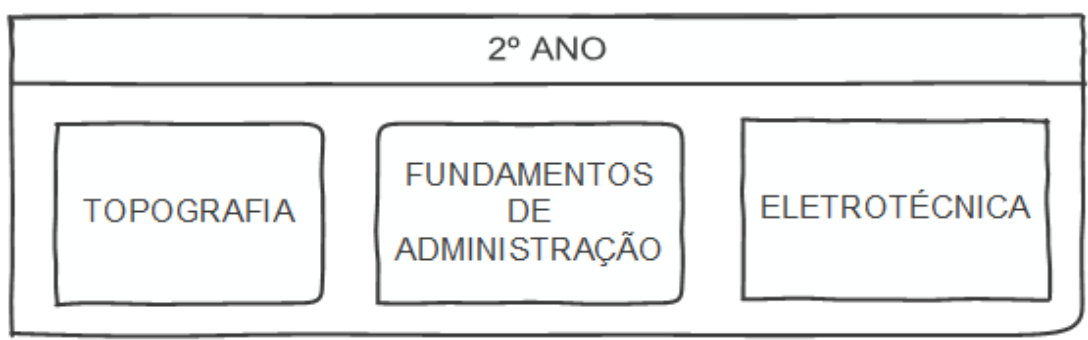

Figura 02: Disciplinas do $2^{\circ}$ ano do curso de engenharia que podem ser relacionadas a metodologia BIM.

Na disciplina de topografia, os avanços tecnológicos devem ser mostrados por meio de levantamento com drones, escaneamento a laser e modelagem de nuvem de pontos, onde poderia ser trabalhado o entorno do projeto desenvolvido na disciplina de desenho para a engenharia, sempre integrando as disciplinas. Com efeito, na disciplina de eletrotécnica, desenvolveria-se o projeto elétrico baseado no projeto da disciplina de desenho para engenharia, e assim o conhecimento seria construído gradativamente a cada etapa do curso de maneira complementar e com um sentido mais evidente. Tangente a isso, na disciplina de fundamentos 
de administração, tendo em vista o perfil empreendedor que se faz necessário no cenário atual, sobretudo pela grande quantidade de profissionais de engenharia que acabam abrindo o próprio negócio, ou ainda, que ocupam cargos de gestão em empresas, propõe-se que, além da teoria geral da administração que segundo Chiavenato (2004), estuda a administração das organizações e empresas do ponto de vista da interação e da interdependência entre seis variáveis principais: tarefa, estrutura, pessoas, tecnologia, ambiente e competitividade, abordada de forma ativa, seja inserida a introdução a metodologias ágeis e seja trabalhada a prática de modelagem de negócios, bem como, metodologias de gestão mais usadas na esfera da engenharia civil.

No caso do terceiro ano do curso (Figura 03), temos a disciplina de Engenharia Econômica, que foca no estudo de simulações financeiras, cálculo de juros e diversos tipos de financiamento, onde poderia ser abordado no contexto financeiro do estudo de viabilidade de empreendimentos, integrando aos conhecimentos da disciplina de Projeto e Construção de Edifícios e Gerenciamento da Construção Civil. Em relação às disciplinas de Projeto e Construção de Edifícios 1 e 2, que tratam de processos construtivos de edificações e da parte de legislação para construção na cidade, encontra-se uma grande oportunidade para a criação de um ambiente integrado de colaboração, onde os discentes possam construir virtualmente edificações conforme os processos construtivos vistos na prática em visitas técnicas, já previstas no plano de ensino da disciplina. Diante disso, pode-se integrar os conhecimentos vistos em disciplinas de semestres anteriores com os conhecimentos adquiridos no decorrer do terceiro ano como, por exemplo, a aplicação de índices urbanos ao projeto, simulações de ventilação e iluminação, etapas construtivas de uma obra, projeto e logística de canteiro de obras, dentre outros, já pensando na integração com a disciplina posterior, de gerenciamento da construção civil (Figura 04) cujo foco é o orçamento de obras, sendo trabalhada a parte de extração de quantitativos automatizada, fluxo de trabalho focados em cada tipo de orçamento, e aplicação de técnicas consagradas de planejamento de obras síncrono com a metodologia BIM utilizando o 4D e o $5 \mathrm{D}$.

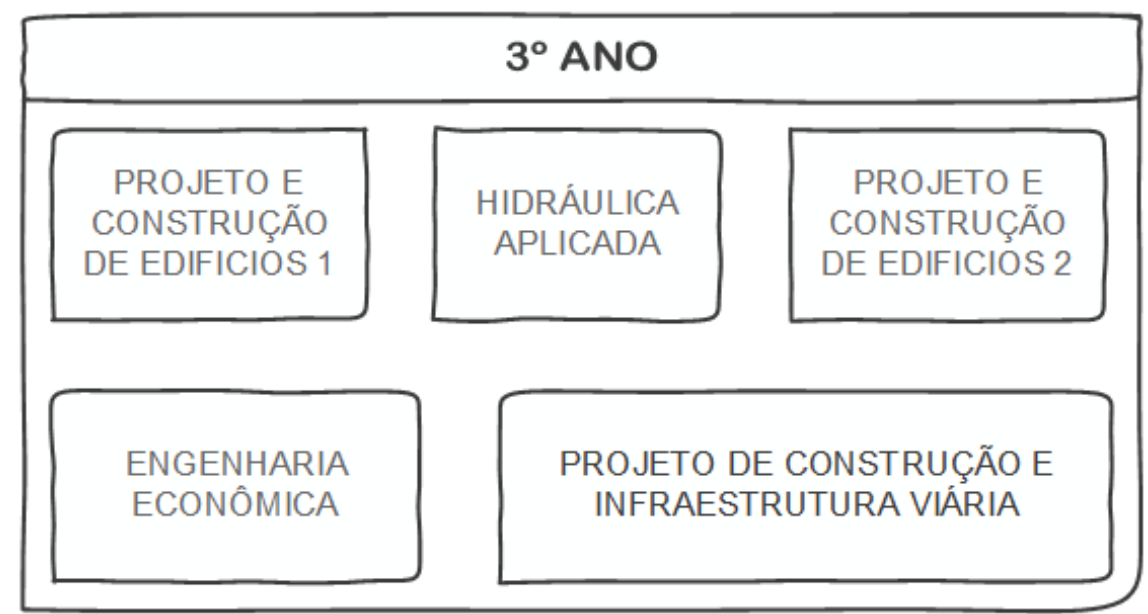

Figura 03: Disciplinas do $3^{\circ}$ ano do curso de engenharia que podem ser relacionadas a metodologia BIM.

Ainda no setor da construção civil, temos as disciplinas da Figura 04, Estruturas de Concreto 01 e 02 em conjunto com as disciplinas de Análise de Estruturas 01 e 02, nas quais são realizados o dimensionamento e a análise de um projeto de estrutura de concreto armado, que poderia ser o mesmo projeto adotado nas disciplinas de Projeto e Construção de Edifícios 
e Gerenciamento na Construção Civil, integrando-se ainda com as outras disciplinas, prevendo projeto de furos por exemplo.

Pensando no setor de BIM voltado para obras de infraestrutura, indo ao encontro da estratégia BIM BR e ao recente marco legal do saneamento, que estabelece que será garantido o acesso à água potável a 99\% da população brasileira e $90 \%$ de acesso ao saneamento básico até 31 de dezembro de 2033 (BRASIL, 2020), espera-se uma demanda crescente no setor e simultaneamente o aumento da eficiência das atividades envolvidas para que a meta seja batida. Nesse cenário, os conhecimentos deverão ser transmitidos aos discentes de forma transversal, iniciando pelas disciplinas de Topografia (Figura 02) e percorrendo as disciplinas relacionadas ao setor posteriormente, como hidráulica aplicada, na qual seria construído um projeto de rede de abastecimento de água locado em um ambiente real. Tangente a isso, na disciplina de Projeto e Construção de Infraestrutura Viária, seria desenvolvido no mesmo ambiente, o projeto das vias do local, pensando-se inclusive nas etapas de projeto integrado e execução das obras. Em seguida, temos a disciplina de Operação e Sistema de Transportes, que poderia ser trabalhada com base no projeto de infraestrutura viária realizado anteriormente, com o foco em simulações de tráfego por meio de ferramentas computacionais no contexto da metodologia BIM. Ainda no setor de infraestrutura, temos a disciplina de Hidrologia, onde temos a integração da metodologia BIM e SIG - Sistema de Informação Geográfica, dando embasamento para as disciplinas de Saneamento e Barragens. Nesse contexto, na disciplina de hidrologia é iniciado o projeto de um reservatório focando nos estudos hidrológicos que podem ser continuados na disciplina de Barragens, na qual, ao final, o projeto executivo de uma barragem é desenvolvido juntamente com um memorial descritivo, tal qual é praticado no mercado de trabalho, além disso durante o desenvolvimento da disciplina, seriam incorporadas uma sequência de ferramentas computacionais de simulação e modelagem para garantir a consistência do projeto. Tangente a isso, temos as disciplinas de Saneamento, que tratam de redes de abastecimento de água, drenagem e esgoto, que, em sua composição, se baseia em estudos hidrológicos para o desenvolvimento do dimensionamento de equipamentos urbanos, sobretudo, de drenagem. Esses projetos podem ser integrados com ferramentas BIM para criar um ambiente colaborativo, e desenvolvendo projetos compatibilizados.

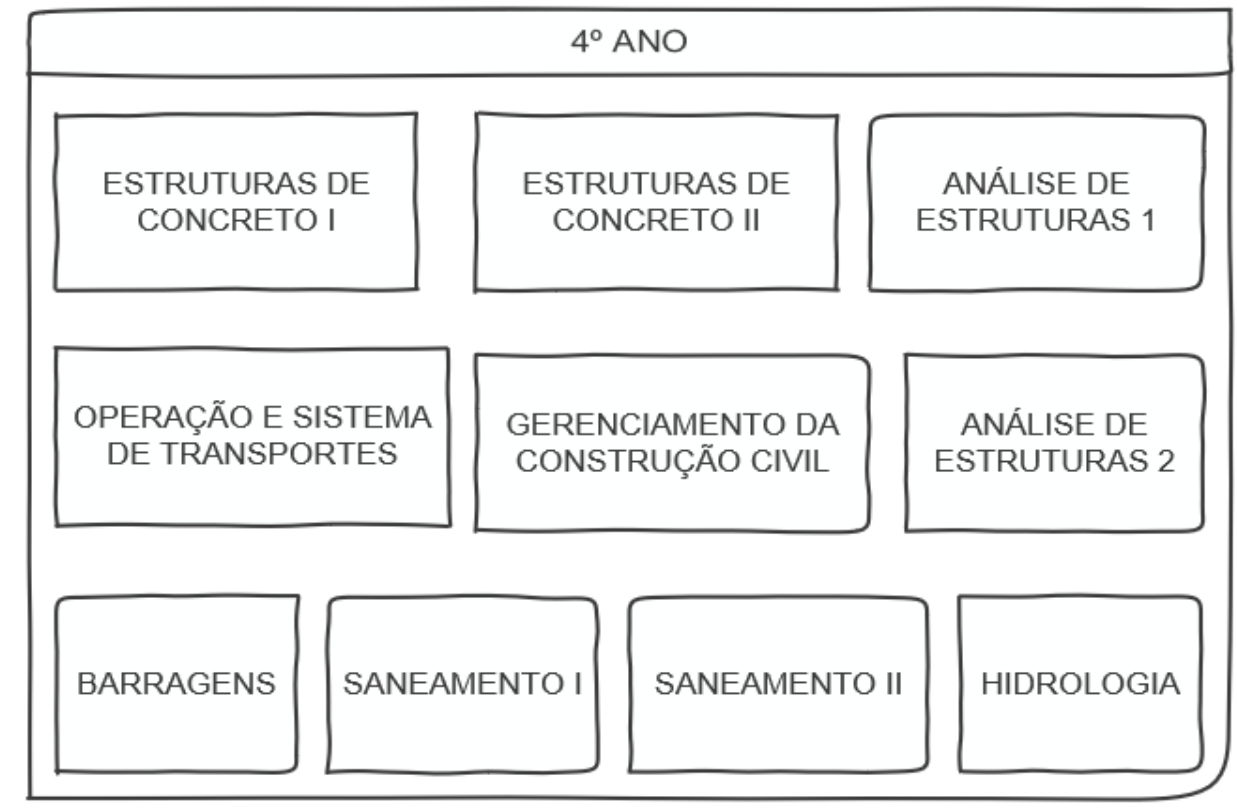

Figura 04: Disciplinas do $4^{\circ}$ ano do curso de engenharia que podem ser relacionadas a metodologia BIM. 
O processo de implantação se dará no período de 5 anos, onde o primeiro ano do processo será voltado para a capacitação dos docentes envolvidos e estruturação na universidade para o início efetivo com os discentes. No segundo ano, será iniciado o processo com os discentes do $1^{\circ}$ ano do curso como piloto e nos anos posteriores serão implementados a cada ano nas turmas subsequentes, onde ao final do $4^{\circ}$ ano da primeira turma a metodologia estará totalmente implementada.

\section{CONSIDERAÇÕES FINAIS}

Considerando a fala de Paulo Freire na qual o ensinar não se trata de transferir conhecimento, mas de criar possibilidades para sua construção, propõe-se uma mudança cujo foco não é na grade curricular em si, mas sim na abordagem de execução por parte do corpo docente, incorporando a metodologia BIM no contexto de desenvolvimento de trabalhos ainda na faculdade, oferecendo a experiência prática que o profissional de engenharia precisa, associando ao desenvolvimento de competências descritas por Bilau Succar como essenciais para o profissional no contexto atual e desenvolvendo habilidades que permeiam a indústria 4.0. É importante ressaltar a importância da atuação de ações de extensão na disseminação do conhecimento de BIM na universidade, seja por meio de eventos como palestras e workshops, ou por meio de capacitações. Na Universidade Federal do Ceará são notáveis as ações de extensão voltadas para BIM, com destaque ao projeto de extensão EPE - Escritório de Projetos Integrados de Engenharia, que vem se mostrando um grande impulsionador do BIM na universidade, com a realização de eventos e com o suporte a inserção de BIM em algumas disciplinas.

Dessa forma, a universidade deve ser um ambiente de aprendizagem efetiva, em que o profissional de Engenharia Civil da Universidade Federal do Ceará corresponda ao que se propõe como peça chave de desenvolvimento da sociedade, e para tanto, este profissional deve adentrar da academia para o mercado, preparado para os desafios que o aguardam.

\section{Agradecimentos}

Gostaríamos de agradecer ao Departamento de Integração Acadêmica e Tecnológica (DIATEC) do Centro de tecnologia da Universidade Federal do Ceará e ao Projeto de extensão Escritório de Projetos Integrados de Engenharia (EPE) vinculado ao departamento, que contribui continuamente com o fomento da metodologia BIM no meio acadêmico e tecnológico.

\section{REFERÊNCIAS}

BARISON, Maria Bernardete, and Eduardo Toledo Santos. "Tendências atuais para o ensino de BIM." Encontro de Tecnologia de Informação e Comunicação na Construção 5 (2011).

BIALON, Lidia; WERNER, Konrad. Fourth Industrial Revolution and Managers cognitive competences. Disponível em: https://content.sciendo.com/view/journals/minib /27/1/article-p81.xml. Acesso em 30 de mai. 2020. 
BRASIL. Presidência da República. DECRETO No 10.306, DE 2 DE ABRIL DE 2020. Disponível em: http://www.in.gov.br/web/dou/-/decreto-n-10.306-de-2-de-abril-de-2020-2510 68946. Acesso em: 31 mai. 2020.

BRASIL. Presidência da República. DECRETO No 14.026, DE 15 DE JULHO DE 2020. Disponível em: http://www.planalto.gov.br/ccivil_03/_Ato2019-2022/2020/Lei/L14026.htm. Acesso em: 31 jul. 2020.

CARUSO, L. Digital innovation and the fourth industrial revolution: epochal social changes?. AI \& Soc 33, 379-392, 2018.

CHIAVENATO, Idalberto. Introdução à teroria geral da administração: Uma visão abrangente da moderna administração das organizações. $7^{\mathrm{a}}$ edição. Rio de Janeiro: Elsevier, 2003.

DE OLIVEIRA CRUZ, M., Cuperschmid, A. R. M., \& Ruschel, R. C. (2017). A incorporação de BIM no ensino do curso Técnico em Edificações. Gestão \& Tecnologia de Projetos, 12(2), 117-134.

FREIRE, P. Pedagogia da Autonomia: Saberes necessários à prática executiva. 41 ed.São Paulo: Paz e Terra, 2010.

KOEHLER,Leonardo P.; BRITO, Jade P. de.; VELLOSO, Márcia P.; LETA, Fabiana R. A contextualização do ensino de engenharia baseada em plantas industriais. In: VII Congresso de Engenharia Mecânica,2012, São Luiz.

LINSINGEN, I. V.; VALE PEREIRA, L. T.; BAZZO, W. A. (1999). Epistemologia e ensino de engenharia. UFSC. Florianópolis. p. 2454-2460.

MINISTÉRIO DA EDUCAÇÃO. Diretrizes curriculares: Cursos de graduação.

Disponível em: http://portal.mec.gov.br/component/content/article?id=12991. Acesso em: 30 mai. 2020.

PEREIRA, A.; SIMONETTO, E. O. Indústria 4.0: Conceitos e perspectivas para o Brasil. Revista da Universidade Vale do Rio Verde, v. 16,n. 1,jan./jul. 2018.

SUCCAR, B \& Sher, W. 2014, A Competency knowledge-base for BIM learning, Australasian Journal of Construction Economics and Building Conference Series, 2(2), 1-10.

UNIVERSIDADE FEDERAL DO CEARÁ. Projeto Pedagógico Do Curso. Disponível em https://si3.ufc.br/sigaa/public/curso/ppp.jsf?lc=pt_BR\&id=657474. Acesso em: 30 mai. 2020.

UNIVERSIDADE FEDERAL DO CEARÁ. Currículos. Disponível em: https://si3.ufc.br/sigaa/public/curso/curriculo.jsf. Acesso em: 30 mai. 2020.

UNIVERSIDADE FEDERAL DO CEARÁ. Portal da UFC. Disponível em: http://www.ufc.br/ensino/guia-de-profissoes/555-engenharia-civil.Acesso em: 30 mai. 2020. 


\title{
SUGGESTED IMPLEMENTATION OF THE BIM METHODOLOGY IN THE CIVIL ENGINEERING COURSE OF THE FEDERAL UNIVERSITY OF CEARÁ
}

\begin{abstract}
:
In the context of Industry 4.0, we need to develop solutions for the pains that arise every day in the global sphere more and more quickly. Therefore, in the Civil Engineering sector, especially in the formation of the Federal University of Ceará, the professional finds it difficult to act satisfactorily with the range of technologies that has been emerging and the university's lethargy in accompanying this progress in the process of building the professional. This work aims to propose a suggested implementation of the BIM methodology in an integrated way in the curriculum of the Civil Engineering course at the Federal University of Ceará. The methodology consisted of the bibliographic review of the Pedagogical Political Project-PPP, as well as the National Curricular Guidelines-DCNs, in the bibliographic review of competences, skills that relate to the BIM methodology, as well as active teaching-learning methodologies enshrined in pedagogy. It is expected that the contribution will help in the curriculum reform process of the Civil Engineering course in which the professional has a more up-to-date training and closer to the reality in which we live.
\end{abstract}

Keywords: BIM, Civil Engineering, UFC, Active methodology, teaching. 